\title{
Efficient Topology for DC-DC Boost Converter Based on Charge Pump Capacitor for Renewable Energy System
}

\author{
Muhammad Zeeshan Malik ${ }^{D},{ }^{1}$ Vineet Tirth ${ }^{D},{ }^{2,3}$ Amjad Ali ${ }^{D},{ }^{4}$ Ajmal Farooq ${ }^{D},{ }^{5}$

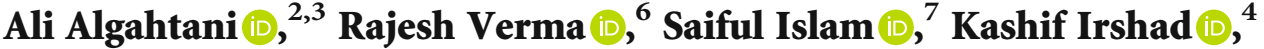 \\ and Ahmed N. Abdalla $\mathbb{D D}^{8}$ \\ ${ }^{1}$ Faculty of Automation, Huaiyin Institute of Technology, Huai'an, 223003 Jiangsu, China \\ ${ }^{2}$ Mechanical Engineering Department, College of Engineering, King Khalid University, Abha 61411, Saudi Arabia \\ ${ }^{3}$ Research Center for Advanced Materials (RCAMS) King Khalid University, P.O. Box 9004, Abha 61413, Saudi Arabia \\ ${ }^{4}$ Centre of Research Excellence in Renewable Energy (CoRE-RE), King Fahd University of Petroleum and Minerals, \\ Dhahran 31261, Saudi Arabia \\ ${ }^{5}$ Department of Electrical Engineering, University of Engineering \& Technology Mardan, Pakistan \\ ${ }^{6}$ Electrical Engineering Department, College of Engineering, King Khalid University, Abha, 61411 Asir, Saudi Arabia \\ ${ }^{7}$ Civil Engineering Department, College of Engineering, King Khalid University, Abha, 61411 Asir, Saudi Arabia \\ ${ }^{8}$ Faculty of Electronic Information Engineering, Huaiyin Institute of Technology, Huai'an, Jiangsu, China
}

Correspondence should be addressed to Muhammad Zeeshan Malik; malik4one@yahoo.com

Received 13 October 2020; Revised 21 December 2020; Accepted 5 February 2021; Published 15 February 2021

Academic Editor: Francesco Riganti-Fulginei

Copyright (c) 2021 Muhammad Zeeshan Malik et al. This is an open access article distributed under the Creative Commons Attribution License, which permits unrestricted use, distribution, and reproduction in any medium, provided the original work is properly cited.

\begin{abstract}
In an attempt to meet the global demand, renewable energy systems (RES) have gained an interest in it due to the availability of the resources, especially solar photovoltaic system that has been an importance since many years because of per watt cost reduction, improvement in efficiency, and abundant availability. Photovoltaic system in remote and rural areas is very useful where a grid supply is unavailable. In this scenario, power electronic converters are an integral part of the renewable energy systems particularly for electronic devices which are operated from renewable energy sources and energy storage system (fuel cell and batteries). In this article, a new topology of charge pump capacitor (CPC) which is based on high voltage gain technique DC-DC boost converter (DCBC) with dynamic modeling is proposed. To testify the efficacy of the introduced topology, a prototype has been developed in a laboratory, where input was given 10VDC and 80VDC output voltage achieved at the load side. Furthermore, the experimental result shows that the voltage stress of MOSFET switches is very less in comparison with the conventional boost converter with the same parameters as the proposed converter.
\end{abstract}

\section{Introduction}

Solar photovoltaic (PV) that has a tremendous potential to generate electricity directly from the sunlight is considered as a means of powering the future with clean and environment friendly renewable sources [1-3]. However, photovoltaic panels, batteries, and fuel cell output voltage are less. To overcome this issue, DC-DC boost converter is installed to step up the low input voltage to require higher output voltage gain as depicted in Figure 1 [4]. The world surpasses in an approximation of 900 million mobile devices with over 500 million users in 2019. With higher energy demand and increasing prices of conventional electricity, it becomes a challenge for the telecommunication service providers to maintain their existing infrastructure as well as to expand it in many rural locations where access to conventional electricity is not east due to many reasons. Due to technological development in renewable energy technologies specifically solar and wind, this proved as an economical and reliable sources to power the telecom systems in remote locations 


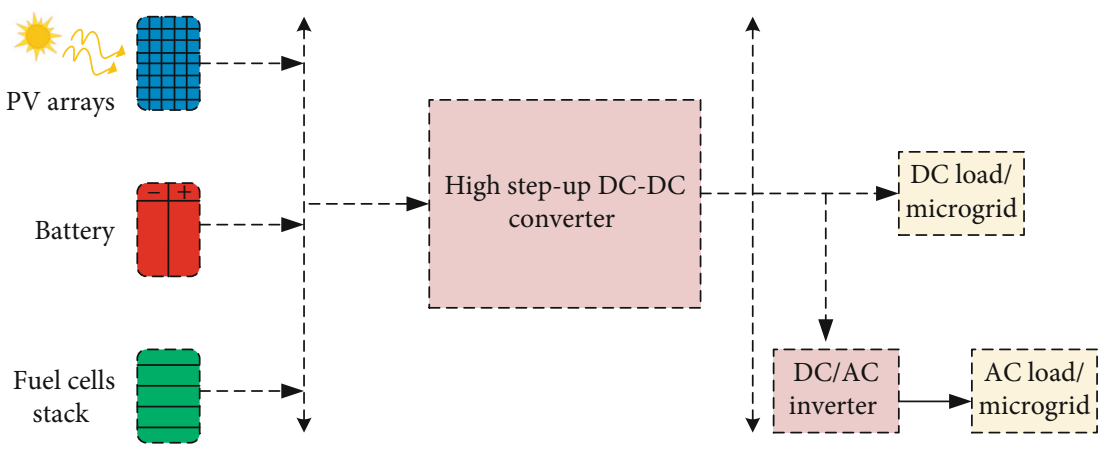

FIGURE 1: Renewable energy system [4].
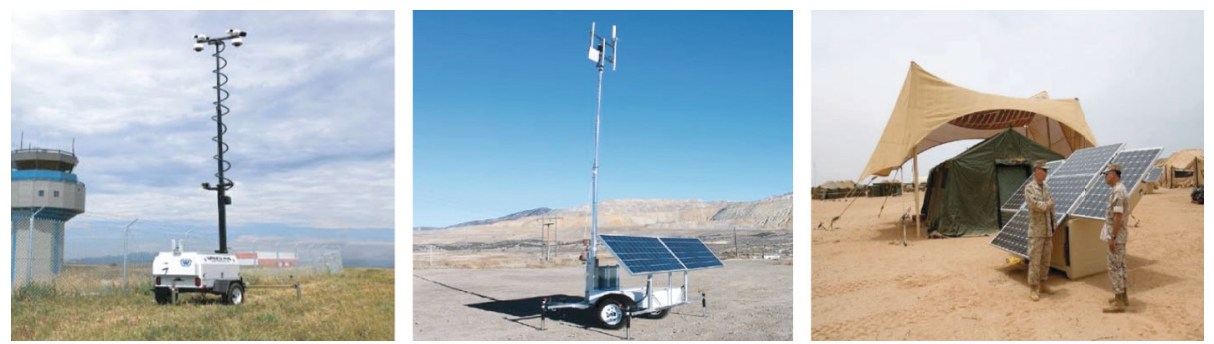

Figure 2: Solar remote power station [5].

where conventional grid access is unavailable or difficult to provide, as well as solar power can provide the protection to the defense communication system from any damage or cyberattack as compared to the electric grid as shown in Figure 2 [5]. Therefore, it is significant to use PV technology (off-grid, on-grid, and remote solar power station). In this scenario, a high step-up boost converter has an important part $[6,7]$. In literature, many types of boost converter introduced to attain the step-up voltage at the load [8]. These converters are operated with very high duty cycle which caused to increase the converter losses; also, many circuit components occur to reduce the overall system efficiency [9]. In the high PWM signal, MOSFET switches cause the malfunction because of short conduction time $[10,11]$. Compared with a classical buck, boost, and buck-boost circuits, transformer-based converters can achieve higher conversion ratios with lower losses $[12,13]$. The same feature applies to converters with coupled inductors [14].

The turn's proportion of the transformer or the coupled inductors helps realize higher stepping ratios $[15,16]$.

DC to DC boost converter with coupled inductor $[17,18]$ and active clamp flyback converter in [19], the main limitation of these converters is the problems related to the transformer. The massive turn's ratio and high-voltage isolation requirements increase the leakage inductance and parasitic capacitance of the winding. At switching instants, the transformer parasitic will result in high voltage spikes across the switches [20]. The voltage and current spikes lead to increased losses and reduced reliability and may damage circuit components [21-23]. A study of some DC-DC converter is discussed in detailed [24]. It described that full-bridge converter can be more efficient. The disadvantage of this design is that the soft switchings are hard to achieve. In this con-

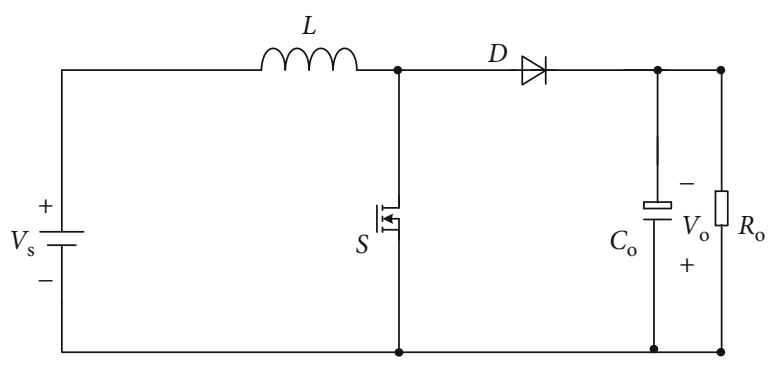

FIgURE 3: Conventional boost converter [27].

verter, there is no suitable value for the snubber capacitors for the whole operation range. Furthermore, in this converter, it needs an output inductor, which can cause voltage spike at diodes. [25].

Finally, DC-DC converter with transformer design is presented in the literature, and the cons of this converter including core losses in the transformer can be significantly high, and the design of winding for transformer is complicated; also, efficiency is low and price is high. Switching semiconductor devices have exacerbated this issue as higher transformer core loss at high switching frequencies make it difficult to size the transformer while simultaneously increasing power density appropriately. Additionally, the inherent mutual coupling effect between adjacent transformer windings makes these topologies less suited to multi-input or multioutput type of applications [26-28]. However, this problem can only be addressed by connecting snubber circuits to the switches or by utilizing the transformer parasitic as a resonant tank and operating these converters as resonant soft-switched converters. 


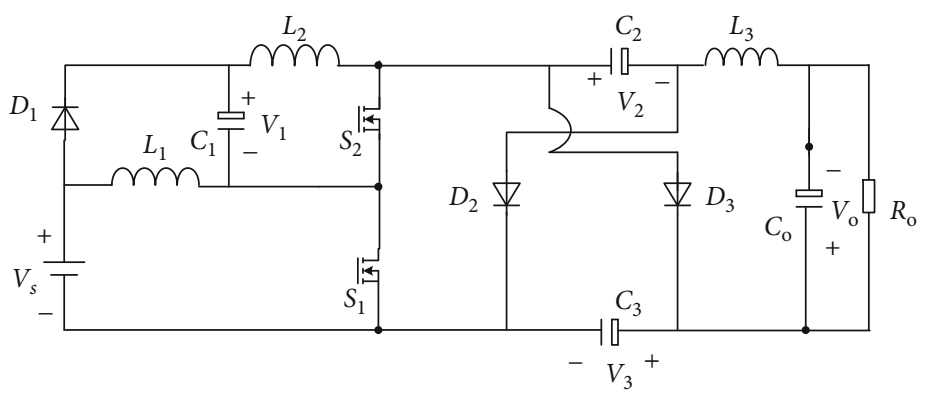

FIgURE 4: Proposed converter.

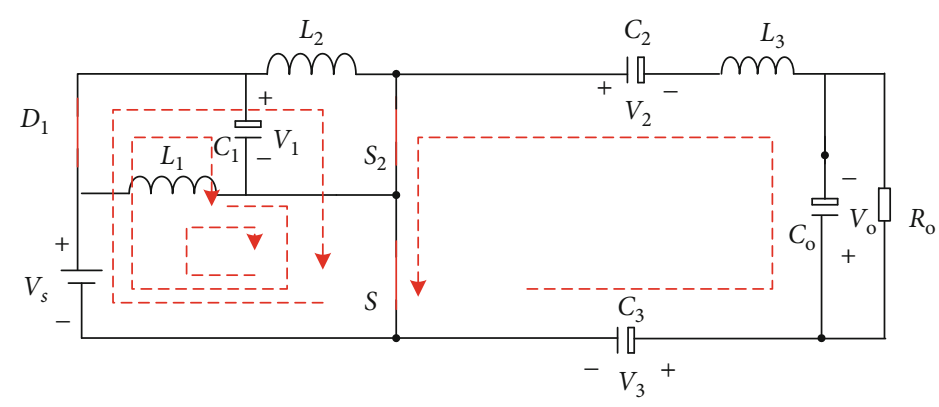

Figure 5: State I.

\section{Related Work}

2.1. The Principle of Boost Converter Circuits. The popular and generally used converters are the conventional DC-DC boost converters. The fundamental thought of these conventional boost converter circuits governed by splitting the input DC voltage with a precise PWM signal to produce an anticipated voltage at the load side. The PWM signal of conventional boost converters generally kept at a constant rate. Figure 3 illustrates the conventional DC-DC boost converter circuit [27]. These circuits are modest in assembly but undergo from some limits avoiding their usage in high-power applications. For the higher DC voltage conversion ratio, conventional converters work with higher duty cycle, which results in increasing the losses in the circuit components and tend to degrade the overall system efficiency $[29,30]$. The higher duty cycle may also cause failure in switches due to the short conduction time [31].

$$
\begin{aligned}
& M=\frac{1}{1-D} V s, \\
& V_{S-\text { tress }}=V_{0} .
\end{aligned}
$$

In Eqs. (1), (2) where $D$ is the duty ratio of the active switch, however, the actual conversion ratio is much lower when the effect of inductor equivalent series resistance $R_{L}$, diode forward voltage drop $V_{D}$, diode forward resistance $R_{d}$, switch on-state resistance $R_{\text {on }}$ is accounted [28]. The effect of all these nonidealities is that the voltage gain from input to output is rarely more than 1.5 to 2 .

\section{The Proposed Method}

3.1. The Circuit Description. This paper presents new DCDC boost converters based on the charge pump capacitor for high voltage gain. The feature combination of CPCDCBC with voltage multiplier cell (CPC) does not exist in any available high voltage gain topologies of DC-DC converter. The main advantage of the introduced topology is it has the capability to achieve high voltage gain without working at higher duty ratio.

The essential features of the proposed converters are proved experimentally in the laboratory with low switching losses and single stage without high-current chopping. Construction of the recommended converter is given in Figure 4 , where $V_{s}$. is an input voltage, four capacitors $\left(C_{1}, C_{2}, C_{3}\right.$, and $\left.C_{0}\right)$, two MOSFET switches $\left(S_{1}\right.$ ad $\left.S_{2}\right)$, inductors $\left(L_{1}, L_{2}\right.$, and $\left.L_{3}\right)$, and diodes $\left(D_{1}, D_{2}\right.$, and $\left.D_{3}\right)$. The presented topology operates in continuous conduction mode (CCM), where all components work in idle condition.

\section{The Operating Principle}

4.1. State $I\left(t_{0}-t_{1}\right)$. In this state, as depicted in Figure 5, when switches $S_{1}$ and $S_{2}$ are on, diode $D_{1}$ works in forward biased, and diodes $D_{2}$ and $D_{3}$ work in reverse biased, respectively. Inductor $L_{1}$ increase by input voltage and inductor current increases linearly at the same time $\left(V_{s}\right)$ established across the inductor $L_{2}$ and the inductor current increases linearly, respectively. In this state, capacitors $V_{\mathrm{C} 1}$ and $V_{C 2}$ work in series resultant capacitor voltage of $V_{C 1}$ $+V_{C 2}=2 V_{C 2}$ inductor $L_{3}$ decrease by $2 V_{C 2}-V_{0}$ and 


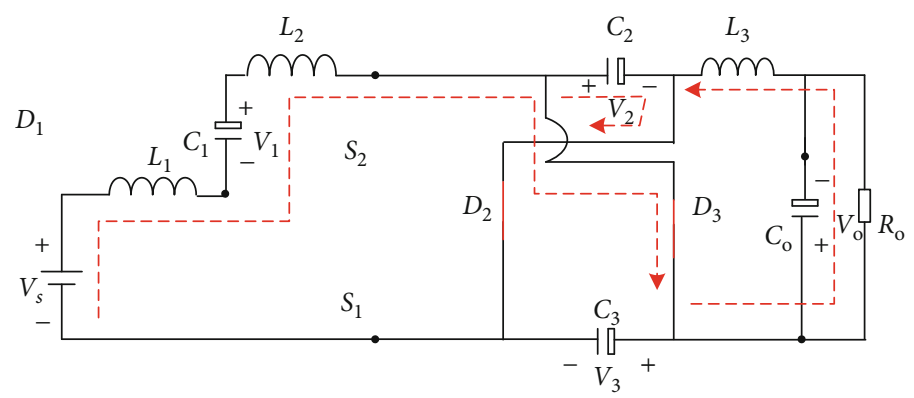

FIGURE 6: State II.
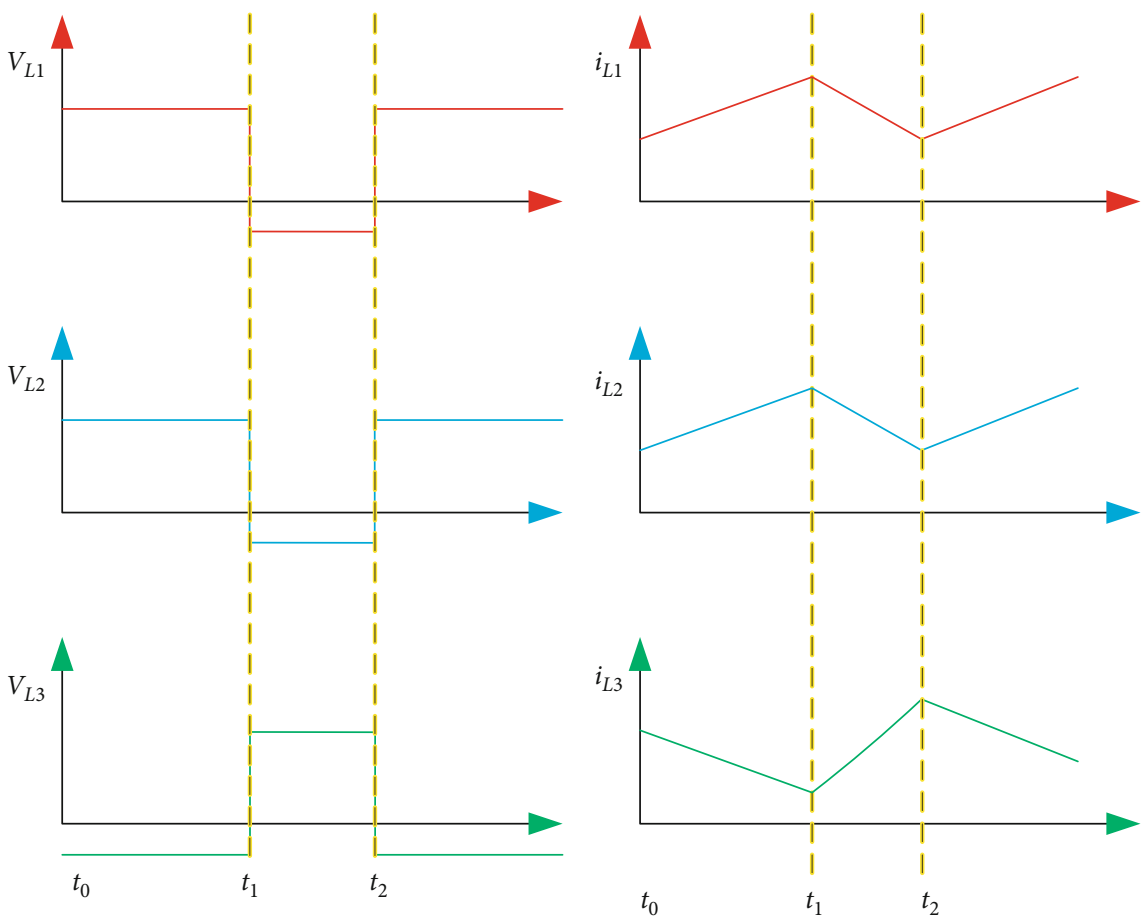

Figure 7: Steady state.

their current decrease in this state. This state is derived in Eqs. (3)-(8).

$$
\begin{gathered}
V_{1}=V_{s}, \\
i_{L 1}=i_{L 1-t_{0}}+\frac{V_{s}}{L_{1}} t \\
i_{L 2}=i_{L 2-t_{0}}+\frac{V_{s}}{L_{2}} t \\
i_{L 3}=i_{L 3-t_{0}}+\frac{2 V_{c 2}-V_{0}}{L_{3}} t, \\
i_{Q 1,2}=i_{L 1}+i_{L 2}+i_{L 3}, \\
i_{\text {in }}=i_{Q}-i_{L 3} .
\end{gathered}
$$

4.2. State II $\left(t_{1}-t_{2}\right)$. In this state, as depicted in Figure 6 , when both the semiconductor switches $S_{1}$ and $S_{2}$ are turned off, diode $D_{1}$ is reverse biased. The current across the inductor
$L_{1}$ discharged to the load by $2 V_{s}-V_{c 2}$.In the same time inductor, $L_{2}$ also released to load the same as inductor $L_{1}$ and the voltage across inductor $L_{3}$ charged to load by $V_{C 2}-$ $V_{0}$. In this state, inductors $i_{L 1}$ and $i_{L 2}$ decrease linearly and $i_{L 3}$ increases respectfully; this state is derived Eqs. (9)-(13).

$$
\begin{gathered}
i_{L 1}=i_{L 1-t_{1}} \frac{2 V_{s}-V_{c 2}}{L_{1}} t, \\
i_{L 2}=i_{L 2-t_{1}} \frac{2 V_{s}-V_{c 2}}{L_{2}} t, \\
i_{L 3}=i_{L 3-t_{1}} \frac{V_{c 2}-V_{0}}{L_{3}} t, \\
i_{Q}=0, \\
i_{\text {in }}=i_{L 2} .
\end{gathered}
$$


TABLE 1: Power/component.

\begin{tabular}{lc}
\hline Power $(\mathrm{W})$ & Components \\
\hline$P_{L 1}$ & $L_{1}$ \\
$P_{L 2}$ & $L_{2}$ \\
$P_{L 3}$ & $L_{3}$ \\
$P_{C 1}$ & $C_{1}$ \\
$P_{C 2}$ & $C_{2}$ \\
$P_{C 3}$ & $C_{3}$ \\
$P_{C 0}$ & $C_{0}$ \\
$P_{D 1}$ & $D_{1}$ \\
$P_{D 2}$ & $D_{2}$ \\
$P_{D 3}$ & $D_{3}$ \\
$P_{S 1}$ & $S_{1}$ \\
$P_{S 2}$ & $S_{2}$ \\
$P_{S^{\prime} 1}$ & $S_{1}^{\prime}$ \\
$P_{S^{\prime} 2}$ & $S_{2}^{\prime}$ \\
\hline
\end{tabular}

\section{Proposed Converter Voltage Conversion Ratio}

At the proposed converter inductors $L_{1}, L_{2}$, and $L_{3}$, applying volt second balance method in each state, the connection between the proposed converters is given below in Eqs. (14)-(20). Steady-state behavior of inductor voltage and their currents are depicted in above Figure 7.

$$
\begin{gathered}
V_{L 1}=V_{s}, \\
V_{L 2}=V_{s}, \\
V_{L 3}=2 V_{c 2}-V_{0}, \\
V_{L 1}=2 V_{s}-V_{c 1}, \\
V_{L 2}=2 V_{s}-V_{c 2}, \\
V_{L 3}=V_{c 2}-V_{0}, \\
G=\frac{V_{0}}{V_{s}}=2 \frac{1+D}{1-D},
\end{gathered}
$$

Voltage stress across the MOSFET switch in Eqs. (21)-(24)

$$
\begin{gathered}
V_{S 1,2}=\frac{1}{3.2} V_{0}, \\
V_{D 1 \text { (stress) }}=V_{1}=-V_{c 1}=-V_{s}, \\
V_{D 2 \text { (stress) }}=V_{2}=-V_{c 2}=-\frac{2 V_{s}}{1-D}, \\
V_{D 3 \text { (stress) }}=V_{3}=-V_{c 3}=-\frac{2 V_{s}}{1-D} .
\end{gathered}
$$

5.1. Proposed Converter Power Loss Analysis. Total power loss in converter is equal to losses in each component of converter Table 1.

$$
\begin{aligned}
& P_{\text {loss }}=P_{L 1}+P_{L 2}+P_{L 3}+P_{C 1}+P_{C 2}+P_{C 3}+P_{C 0} \\
& +P_{D 1}+P_{D 2}+P_{D 3}+P_{S 1}+P_{S 2}+P_{S^{\prime} 1}+P_{S^{\prime} 2} \text {. } \\
& P_{L 1}=I_{L 1(\mathrm{rms})}^{2} \cdot R_{L 1} \text {, } \\
& P_{L 2}=I_{L 2(\mathrm{rms})}^{2} \cdot R_{L 2} \text {, } \\
& P_{L 3}=I_{L 3(\mathrm{rms})}^{2} \cdot R_{L 3} \text {, } \\
& P_{C 1}=I_{C 1(\mathrm{rms})}^{2} \cdot R_{C 1} \text {, } \\
& P_{C 2}=I_{C 2(\mathrm{rms})}^{2} \cdot R_{C 2} \text {, } \\
& P_{C 3}=I_{C 3(\mathrm{rms})}^{2} \cdot R_{C 3} \text {, } \\
& P_{C 0}=I_{C 0(\mathrm{rms})}^{2} \cdot R_{C 0} \text {, } \\
& P_{D 1}=I_{D 1(\mathrm{rms})}^{2} \cdot R_{D 1} \text {, } \\
& P_{D 1}=I_{D 1(\mathrm{rms})}^{2} \cdot R_{D 1} \text {, } \\
& P_{D 2}=I_{D 2(\mathrm{rms})}^{2} \cdot R_{D 2} \text {, } \\
& P_{D 3}=I_{D 3(\mathrm{rms})}^{2} \cdot R_{D 3}, \\
& P_{S 1}=I_{s 1(\mathrm{rms})}^{2} \cdot R_{D s(\mathrm{on}) 1} \text {, } \\
& P_{S 2}=I_{s 2(\mathrm{rms})}^{2} \cdot R_{D s(\mathrm{on}) 2}, \\
& P_{S^{\prime} 1}=\frac{1}{2}\left[V_{S 1(\max )} \cdot I_{S 1(\max )} \cdot f_{s} \cdot\left(t_{r}+t_{f}\right)\right. \text {, } \\
& P_{S^{\prime} 2}=\frac{1}{2}\left[V_{S 2(\max )} \cdot I_{S 2(\max )} \cdot f_{s} \cdot\left(t_{r}+t_{f}\right)\right. \text {, }
\end{aligned}
$$

$V_{S 1(\max )}=$ maximum voltage stress of $S_{1}, \quad I_{S 1(\max )}=$ maximum current stress of $S_{1}, f_{s}=$ switching frequency, $t_{r}=$ rise time of MOSFET switch, and $t_{f}=$ fall time of MOSFET switch.

$$
I_{L 1(\mathrm{rms})}=\sqrt{I_{L 1(\mathrm{avg})}^{2}+\left(\frac{\Delta I_{L 1} / 2}{\sqrt{3}}\right)^{2}} .
$$

Similarly, for $I_{L 2}(\mathrm{rms})$ and $I_{L 3}(\mathrm{rms})$,

$$
\begin{gathered}
I_{c 1(\mathrm{rms})}=\frac{I_{C 1(\mathrm{max})}}{\sqrt{3}}=\frac{\Delta I_{L 1} / 2}{\sqrt{3}}, \\
I_{c 2(\mathrm{rms})}=I_{C 3(\mathrm{rms})}=\frac{\Delta I_{L 2} / 2}{\sqrt{3}}, \\
I_{c 0(\mathrm{rms})}=\frac{\Delta I_{L 3} / 2}{\sqrt{3}}, \\
I_{D 1(\mathrm{rms})}=\sqrt{D}\left(I_{s}-I_{L 1}\right), \\
I_{D 2(\mathrm{rms})}=I_{D 3(\mathrm{rms})}=\sqrt{1-D} \cdot\left(I_{L 1}\right), \\
I_{s 1(\mathrm{rms})}=\sqrt{D} \cdot I_{L 1}, \\
I_{s 2(\mathrm{rms})}=\sqrt{D} \cdot I_{L 2} .
\end{gathered}
$$




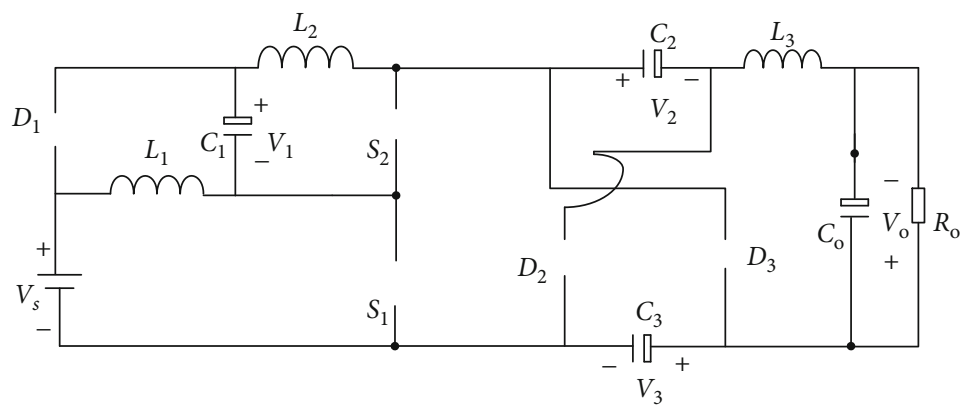

Figure 8: $D_{1} T_{s}->T_{s}$

5.2. DCM Analysis of Proposed Converter. Discontinuous conduction mode (DCM) occurs in switching ripples in inductor current is too large which causes reverse current to flow in the diodes. As we know, didoes can conduct in reverse current so converter goes in DCM mode.

DCM mode commonly occurs in converter which has a single quadrant switch. The condition for CCM operation is that average value of conductor should be greater than half of the peak to peak ripples. Converter can go into DCM as given below.

For CCM mode,

$$
I_{L(\mathrm{avg})}>\frac{\Delta I_{L}}{2}=>2 I_{L(\mathrm{avg})}>\Delta I_{L}
$$

For DCM mode,

$$
I_{L(\operatorname{avg})}<\frac{\Delta I_{L}}{2}=>2 I_{L(\operatorname{avg})}<\Delta I_{L}
$$

In between the above two conditions is the boundary $\mathrm{B} / \mathrm{W}$ CCM and DCM which is given by

$$
I_{L(\operatorname{avg})}=\frac{\Delta I_{L}}{2}=>2 I_{L(\operatorname{avg})}=\Delta I_{L}
$$

In proposed converter, we have three inductors. For CCM inductors, value can be obtained for CCM mode below.

$$
\begin{gathered}
L_{1(\min )}=L_{2(\min )}=\frac{D V_{s}}{2 f_{s} I_{L(\mathrm{avg})}}, \\
L_{3(\min )}=\frac{D\left(2 V_{c 2}-V_{0}\right)}{2 f_{s} I_{L 3(\mathrm{avg})}} .
\end{gathered}
$$

As the energy release path from inductor $L_{3}$ is discharged by switches $S_{1}$ and $S_{2}$, these switches are bidirectional, so there is no DCM mode in inductor $L_{3}$ due to ripples in current. In simple word, ripples increase in $I_{L 3}$ do not cause DCM because MOSFET switches $S_{1}$ and $S_{2}$ conduct the reverse current. However, value of inductor $L_{3}$ should be greater enough to avoid the current reversal problem.

An increase of ripple current theory in inductors $L_{2}$ and $L_{2}$ causes DCM mode as the freewheeling diodes $D_{2}$ and $D_{3}$ cannot conduct the reverse current. Hence, for DCM, there is a $3^{\text {rd }}$ stage in proposed converter which $D_{2}$ and $D_{3}$ also

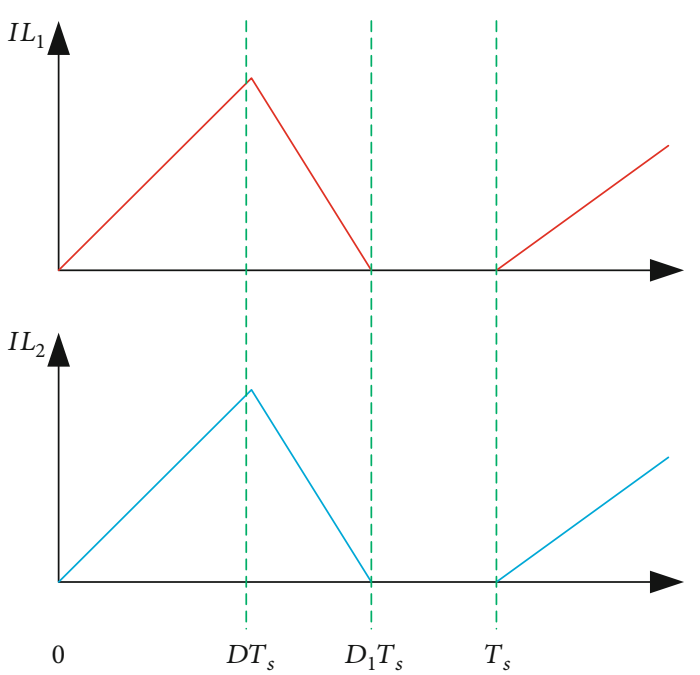

FIGURE 9: Steady state.

of along with other switching components as shown in below Figure 8 .

So in DCM operation of proposed converter, there are three switching states in each switching period. State I and state II are the same as CCM mode, and state III is given below when all switches are off.

$$
\begin{gathered}
I L_{1}=I L_{2}=0, \\
V L_{1}=V L_{2}=0, \\
V L_{3}=V_{3}-V_{0}-V D_{2} .
\end{gathered}
$$

As we know, $V_{3}=V_{2}$ and $V_{s}=V_{1}$, so

$$
V L_{3}=2 V_{2}-2 V_{s}-V_{0}
$$

Current through inductors $L_{1}$ and $L_{2}$ is given below steady state Figure 9.

In DCM mode, DC conversion ratio is given by

$$
M=\frac{V_{0}}{V_{s}}=f\left(D \cdot D_{1}\right)=f\left(D \cdot I_{L(\mathrm{avg})} \cdot L \cdot T_{s}\right) .
$$


After applying voltage second balance law on all inductors, we get

$$
\begin{gathered}
V_{2}=V_{3}=\frac{2 D_{1}}{D_{1}-D} V_{s}, \\
M=\frac{V_{0}}{V_{s}}=\frac{\left(2 D_{1}\right)\left(D+2-D_{1}\right)-\left(2 D_{1}-2\right)\left(D_{1}-D\right)}{D_{1}-D}, \\
D_{1}=\frac{2 L_{1}-D}{D V_{s} \cdot T_{s}} .
\end{gathered}
$$

5.3. Dynamic Modeling for the Presented Converter. For dynamic modeling, ripples of inductor current and voltage ripples of capacitor are assume very less. The equivalent circuit of presented converter is shown below in Figure 10 derived from Figure 5.

Subsequently, applying circuit theory in Figure 7, this derived in Eq. (37).

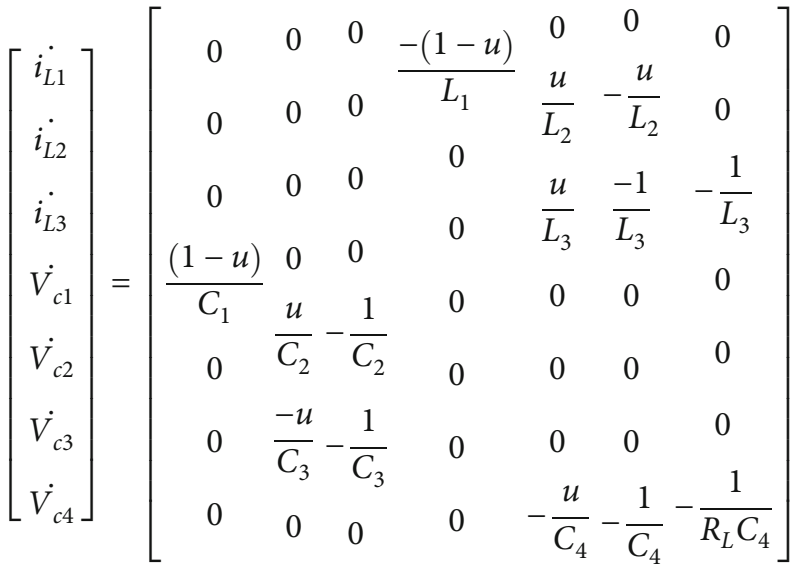

$$
\begin{aligned}
& {\left[\begin{array}{c}
i_{L 1} \\
i_{L 2} \\
i_{L 3} \\
V_{c 1} \\
V_{c 2} \\
V_{c 3} \\
V_{c 4}
\end{array}\right]+\left[\begin{array}{c}
\frac{u}{L_{1}} \\
\frac{1+u}{L_{2}} \\
-\frac{1}{L_{3}} \\
0 \\
0 \\
0 \\
0
\end{array}\right]\left[e_{t}\right]}
\end{aligned}
$$

Equation (37) can be written as Eq. (38) without considering losses.

$$
\dot{x}(t)=A(u) x(t)+B(u) e(t)
$$

where $x_{(t)}=\left[i_{L 1}, i_{L 2}, i_{L 3}, V_{c 1}, V_{c 2}, V_{c 3}, V_{c 4}\right]^{T} \in R^{7}$ is the normal value of state vector, $A_{(u)}$ is a matrix in $R^{7 \times 7}$, and $B_{(u)}$ is a vector in $R^{7} ; V_{s} \in R=$ input voltage, whereas resistive load is $R_{L}$ and $u$ is a function of switch $S$ with the binary value, which is $[0,1]$. This means that when the switch value is [0], the switch is off, and when the value is [1], the switch is on. The above equation is based on nonlinear, and matrix $A_{(u)}, B_{(u)}$ is based on control signal of $u_{(t)} \in R$. The linearisation process method obtained the proposed converter behavior to small perturbations around an operation point. Therefore, the nominal steady-state operating system of the proposed converter can be written by setting (8), $A X+B E=0$ and can be written as shown in Eqs. (49)(55).

The voltage across the capacitor is

$$
\begin{gathered}
V_{c 1}=V s, \\
V_{c 2}=\frac{2}{1-D} V s, \\
V_{c 3}=\frac{2}{1-D} V s, \\
V_{c 4}=2 \frac{1+D}{1-D} V s,
\end{gathered}
$$

Current across the inductor is

$$
\begin{gathered}
i_{L 1}=\frac{V_{s}}{(1-D)^{4} R_{L}}, \\
i_{L 2}=\frac{V_{s}}{(1-D)^{4} R_{L}}, \\
i_{L 3}=\frac{V_{s}}{(1-D)^{2} R_{L}},
\end{gathered}
$$

where $V_{s}=$ DC input voltage and $D=$ duty cycle of the switch $S, \quad \tilde{u}=$ small - signal perturbations to the nominal dusty cycle $D$, and $\tilde{e}=$ to the nominal input voltage $V_{s}$ to the nominal input voltage, so we can write the relationship between voltage and duty cycle as below (46), (47).

$$
\begin{gathered}
e(t)=E+\tilde{e}, \\
u(t)=U+\tilde{u},
\end{gathered}
$$

where $\tilde{e}<<E$ and $\tilde{u}<<D$, so we can also write as (48), (49).

$$
\begin{array}{r}
X(t)=X+\tilde{x}, \\
V_{0}(t)=V_{0}+\tilde{v}_{0} .
\end{array}
$$

After substituting Eqs. (39)-(45) and (46), (47) into Eq. (40), we can derive linear mode after assuming that the 


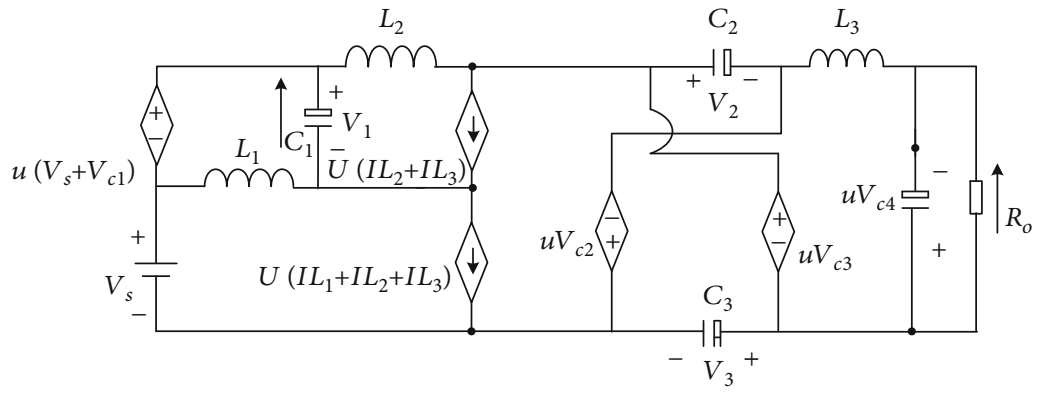

Figure 10: Average equivalent circuit.

perturbations are less enough and nonlinear terms can be avoided so that we can write Eq. (50).

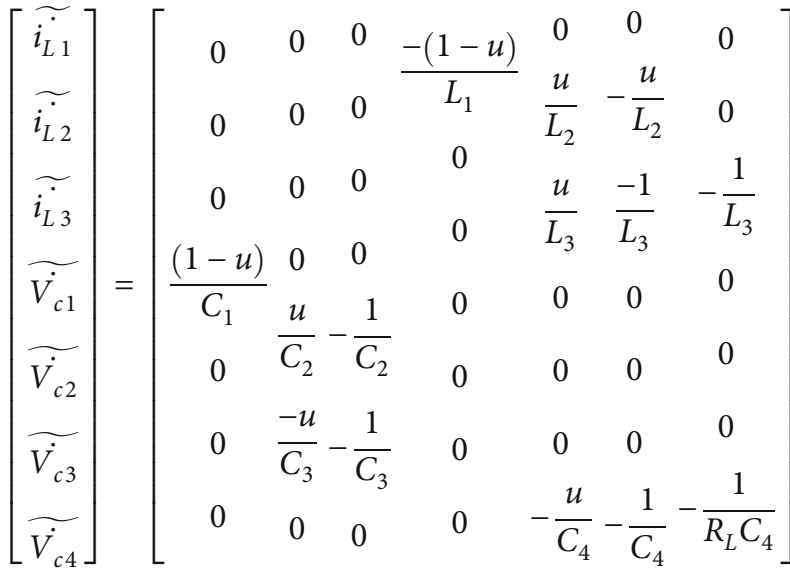

$$
\begin{aligned}
& {\left[\begin{array}{c}
\widetilde{i_{L 1}} \\
\widetilde{i_{L 2}} \\
\widetilde{i_{L 3}} \\
\widetilde{V_{c 1}} \\
\widetilde{V_{c 2}} \\
\widetilde{V_{c 3}} \\
\widetilde{V_{c 4}}
\end{array}\right]+\left[\begin{array}{cc}
\frac{2}{2} V s & \frac{u}{L_{1}} \\
\frac{2}{(1-D) L_{2}} V s & \frac{1+u}{L_{2}} \\
\frac{1+D}{(1-D) L_{2}} V s & -\frac{1}{L_{3}} \\
\frac{V_{s}}{(1-D)^{4} R_{L c 1}} & 0 \\
\frac{V_{s}}{(1-D)^{4} R_{L c 2}} & 0 \\
\frac{V_{s}}{(1-D)^{2} R_{L c 3}} & 0
\end{array}\right]\left[\begin{array}{c}
\tilde{u} \\
\tilde{e}
\end{array}\right] .}
\end{aligned}
$$

Equation (50) can be written as Eq. (51).

$$
\dot{x}(t)=A x(t)+B v(t)
$$

where $x_{(t)} \in R^{7}$ is the state vector, $A \in R^{7 \times 7}$ and $B$ are constant matrix in $R^{7 \times 2}, R^{2}$ is vector of input voltage, and $V_{(t)}=[\tilde{u} \tilde{e}]$. When the perturbation input voltage is neglected $\tilde{e}=0$,so matrix $B$ can be removed and written as (62).

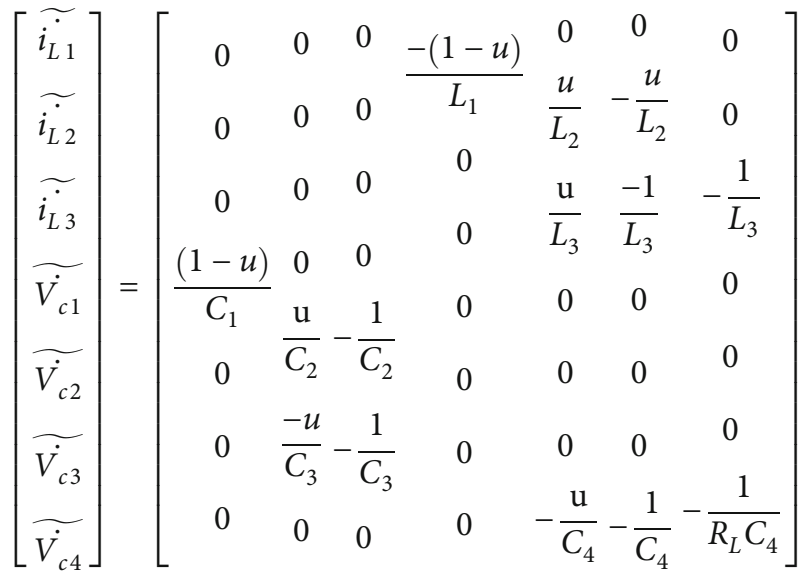

$$
\begin{aligned}
& {\left[\begin{array}{c}
\widetilde{i_{L 1}} \\
\widetilde{i_{L 2}} \\
\widetilde{i_{L 3}} \\
\widetilde{V_{c 1}} \\
\widetilde{V_{c 2}} \\
\widetilde{V_{c 3}} \\
\widetilde{V_{c 4}}
\end{array}\right]+\left[\begin{array}{c}
\frac{2}{\frac{2}{(1-D) L_{2}} V s} \\
\frac{2}{(1-D) L_{2}} V s \\
\frac{1+D}{(1-D) L_{3}} V s \\
\frac{V_{s}}{(1-D)^{4} R_{L c 1}} \\
\frac{V_{s}}{(1-D)^{4} R_{L c 2}} \\
\frac{V_{s}}{(1-D)^{2} R_{L c 3}}
\end{array}\right] \text {. }}
\end{aligned}
$$

\section{Results and Discussions}

6.1. Simulation Results and Discussion. Figures 11(a) and 11(b) presented simulation results of proposed topology and conventional boost converter. These simulation results performed in Matlab Simulink at the same parameters, as 


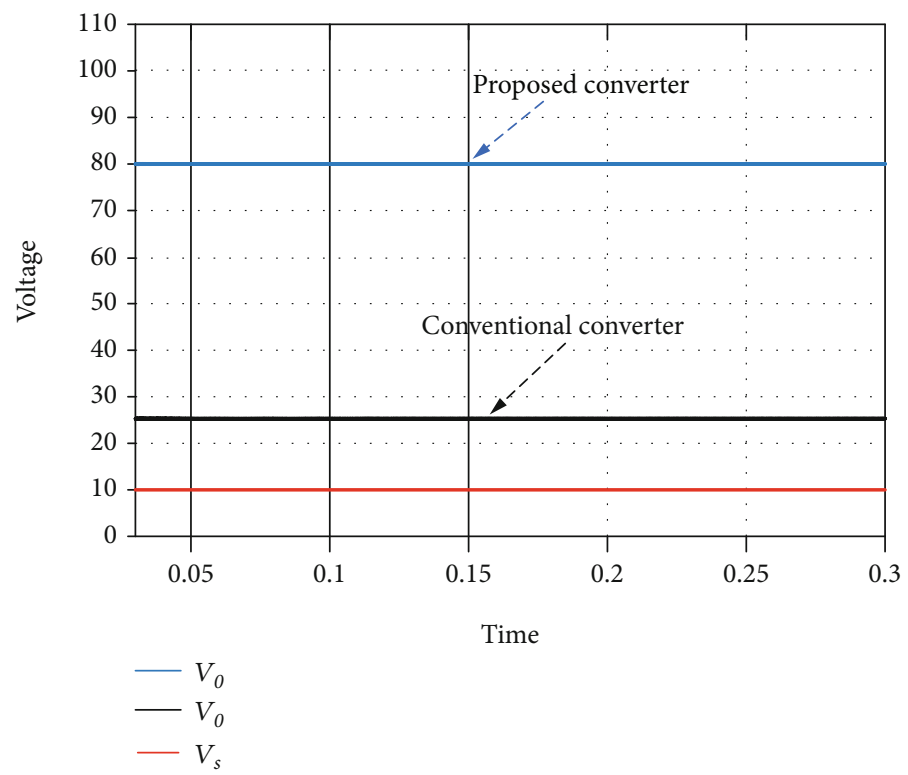

(a)

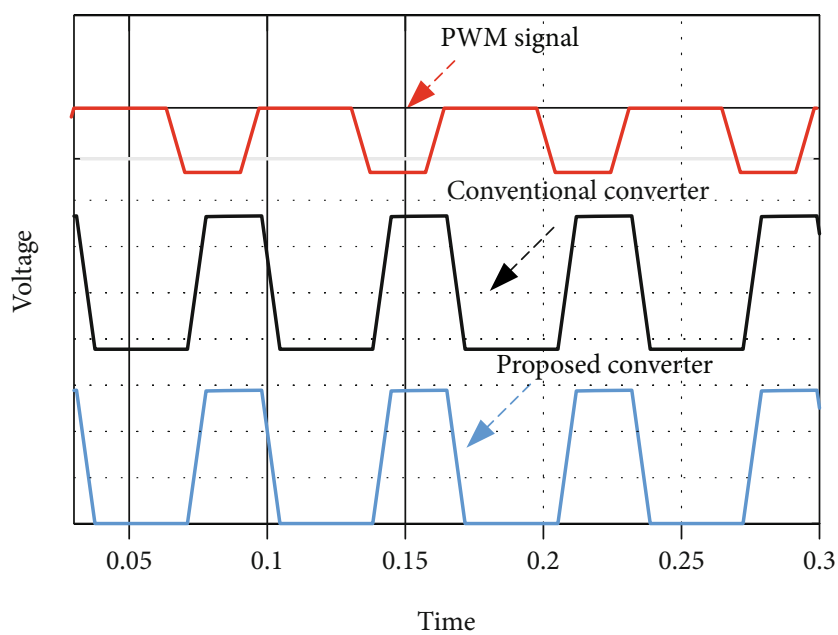

- Voltage stress $25 \mathrm{~V}$

- Voltage stress $25 \mathrm{~V}$

(b)

FIgURE 11: Proposed converter simulation results.

shown. Figure 11(a) shows the simulation results of both the conventional boost converter and proposed CPC converter, where input voltage given to both the converters is the same $10 \mathrm{~V}$, and it can be seen that the output voltage of the proposed converter is higher as compared to conventional converter, which is $80 \mathrm{~V}$ as compared to $25 \mathrm{~V}$ output voltage of conventional boost converter, which is very low. In Figure 11(b), we can see that the voltage stress of the traditional boost converter is the same as output voltage, as mentioned in Eq. (2). Still, the voltage stress of the recommended converter CPC topology is very less. From simulation results, it is very clear that the presented converter contains many pros as compared to conventional converter, such as high voltage gains and lower semiconductor switching stress, as shown in Figure 11(b). In traditional boost converter, if we

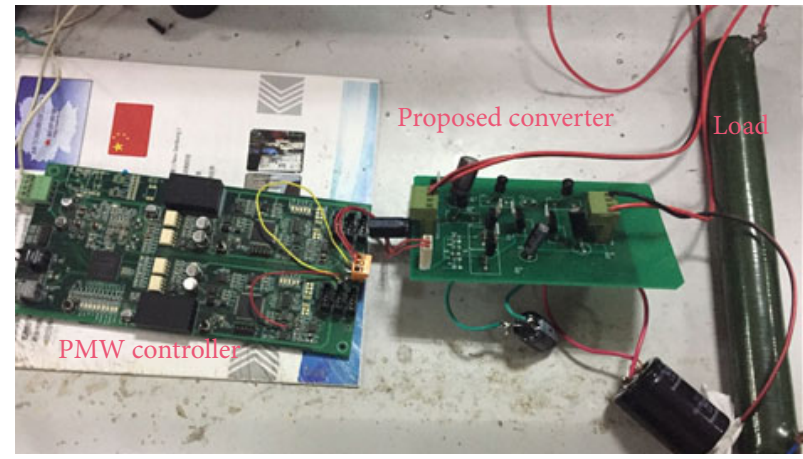

FIGURE 12: Experimental prototype of presented converter. 
TABLE 2: Component type and cost.

\begin{tabular}{lcccc}
\hline Components & Symbol & Component type & Cost $(\$)$ & Model number \\
\hline Inductors $\left(L_{1,2,3}\right)$ & $L$ & Passive & $0.15 /$ piece & \\
Capacitor $\left(C_{1,2,3,4}\right)$ & $C$ & Passive & $\$ 0.20-\$ 1 /$ piece & \\
Resistor & $R$ & Passive & $\$ 14-\$ 20 /$ piece & \\
MOSFET $\left(S_{1,2}\right)$ & $S$ & Active & $\$ 0.22-\$ 0.24 /$ piece & IRFZ46N \\
Diodes $\left(D_{1,2,3}\right)$ & $D$ & Active & $\$ 0.21-\$ 0.24 /$ piece & MUR860 \\
\hline
\end{tabular}

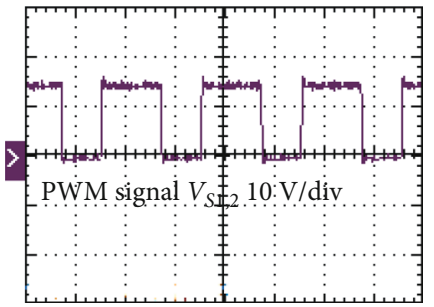

(a)

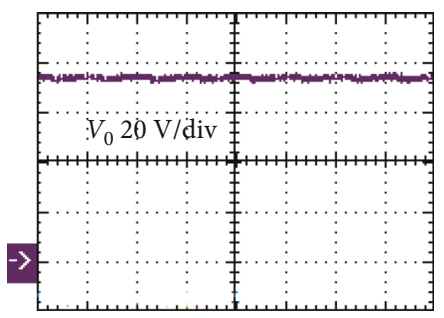

(c)

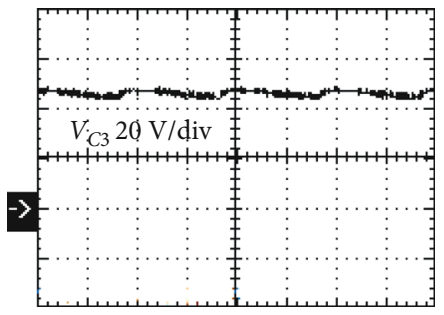

(e)

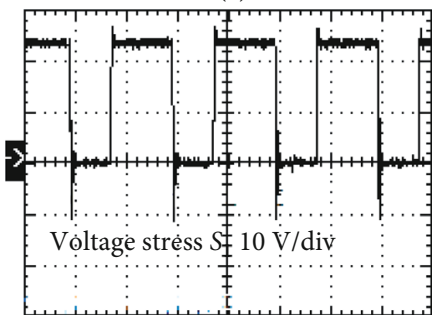

(g)

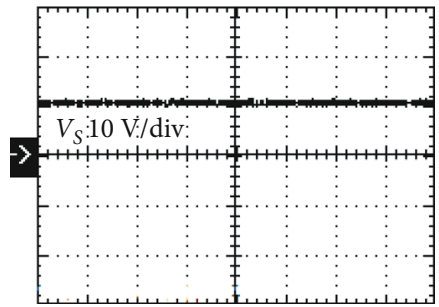

(b)

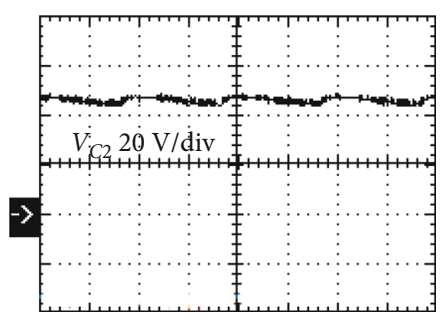

(d)

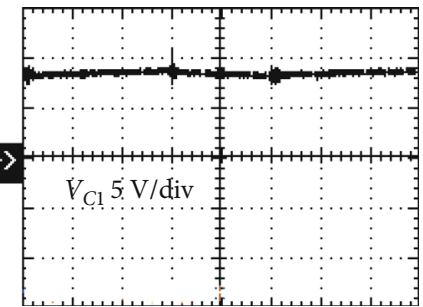

(f)

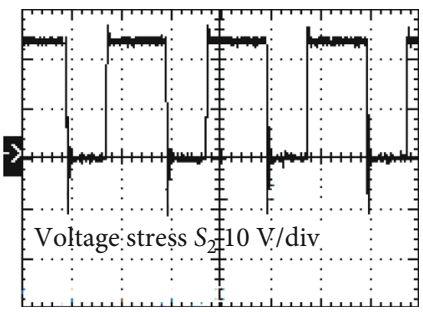

(h)

Figure 13: Proposed converter experimental results.

give $10 \mathrm{~V}$ as an input voltage to achieve the output voltage according to proposed topology from the conventional boost converter, it shall be operated at higher of duty ratio, which will result in increasing the component losses connected with the circuit and will degrade the overall system efficiency. The higher duty cycle could cause failure or malfunctioning of the switches because of the short conduction time.

6.2. Experimental Results and Discussion. To validate the operation principle and investigate the efficacy of the recom- mended CPC converter topology, a lab-scale prototype was developed with the circuit parameters: $V_{S}=10 \mathrm{~V} ; V_{0}=80$ $\mathrm{V}$; switching frequency $=100 \mathrm{kHz} ; L_{1}, L_{2}$, and $L_{3}=220 \mu \mathrm{H}$; load $=200 \Omega ; \quad C_{1}, C_{2}, C_{3}$, and $C_{0}=440 \mu \mathrm{F}, 840 \mu \mathrm{F}, 840 \mu \mathrm{F}$, and $420 \mu \mathrm{F}$, respectively, as shown in Figure 12, and proposed converter component types and cost are presented in Table 2. The experimental results of the recommended CPC converter are depicted in Figure 13, where the duty cycle of the suggested CPC topology is set at $D=0.6$, and it works in CCM mode. Figure 13(a) depicted switching signals 


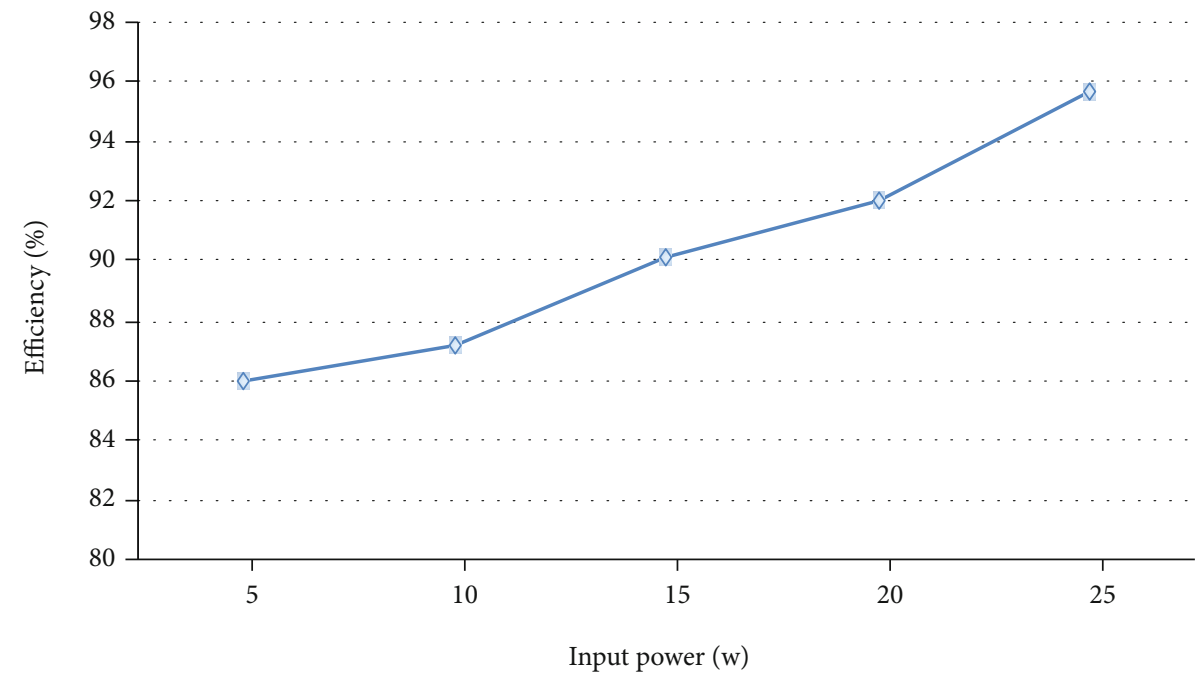

FIGURE 14: Efficiency graph.

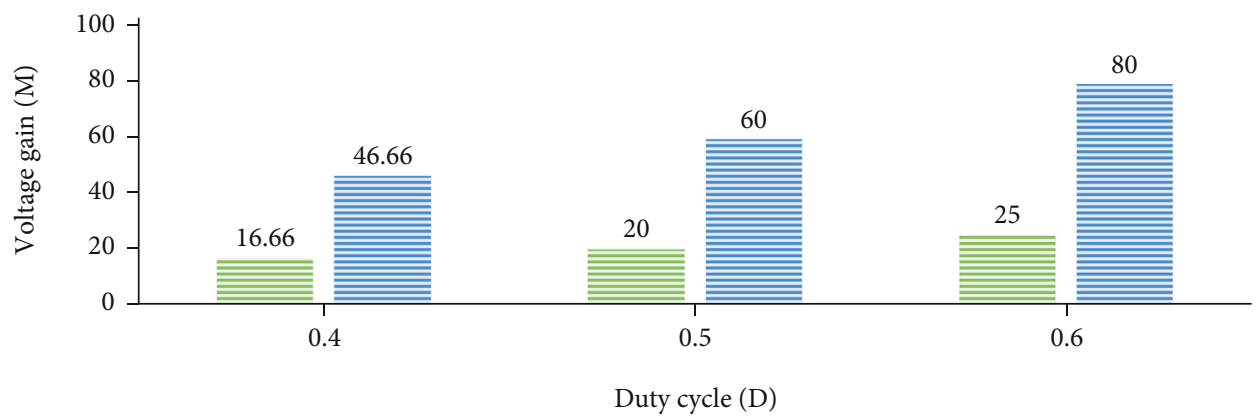

Conventional converter

Proposed converter

FIgURE 15: Voltage gain graph.

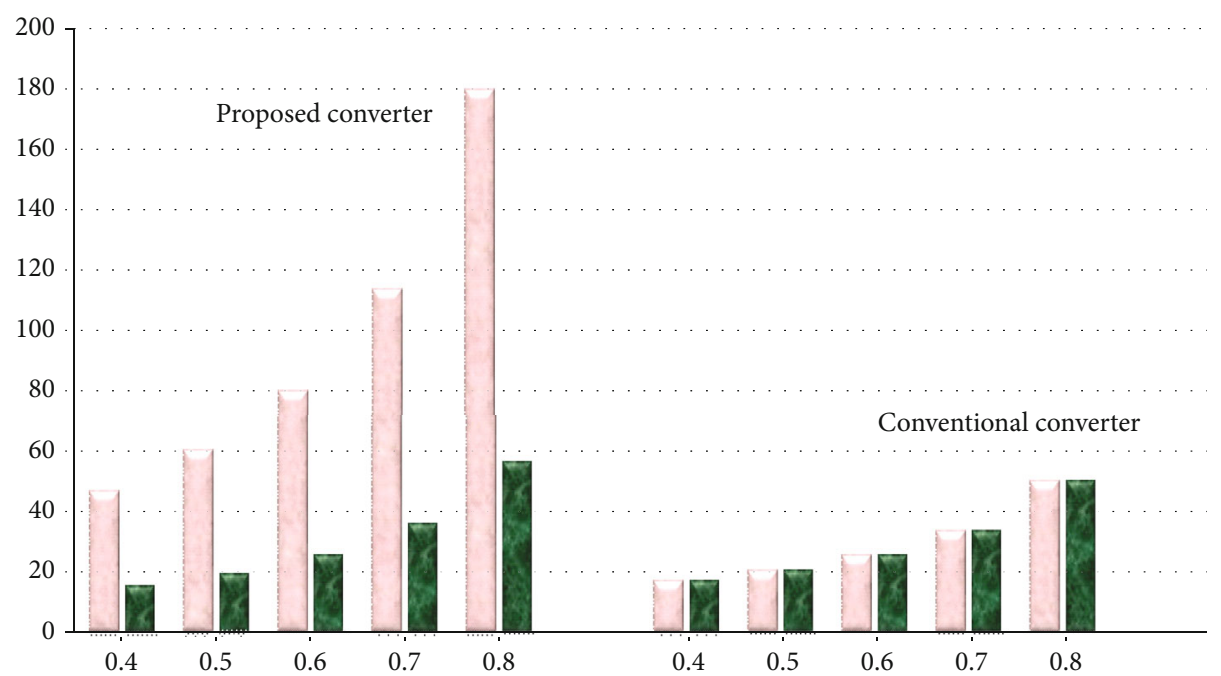

Duty cycle (D)

Output voltage

Voltage stress across the switch

FIGURE 16: Switching stress graph. 
of the anticipated converter, and Figure 13(b) depicted input voltage $V s$. Figure 13(c) depicted where we can observe that the output voltage $V_{0}$ presented converter is around $78 \mathrm{~V}$, which is very close to the voltage gain equation of the recommended converter. From output voltage, it is vibrant that the recommended converter CPC topology has achieved high voltage gain without higher duty ratio.

Figures 13(d) and 13(e) show the waveform of capacitor voltage $V_{C 2}$ and $V_{C 3}$ which is $49 \mathrm{~V}$, respectively, which are also very close to the capacitors of Eqs. (40), (41). Figure 13(f) depicted voltage across the capacitor $V_{C 1}$ which is $10 \mathrm{~V}$, which is equal to the input voltage. Furthermore, Figures $13(\mathrm{~g})$ and $13(\mathrm{~h})$ depicted voltage stress across the MOSFET switches $S_{1}$ and $S_{2}$ which are $25 \mathrm{~V}$ of each. So, it is testified that the recommended CPC converter topology can get high voltage gain at the load side with monomer switching stress.

The proposed converter efficiency vs. the traditional boost converter were observed at different load at input and output terminals in which input voltage and current and output voltage current were measured with a tool, and supported handling data by following the Eq. (53) were performed in Matlab Simulink.

$$
\eta=\frac{V_{0} * I_{0}}{V_{\text {in }} * I_{\text {in }}}
$$

The proposed converter efficiency graph is portrayed in Figure 14, and it can be observed that the maximum efficiency achieved by the proposed CPC topology is $95.68 \%$ at $25 \mathrm{~W}$ input power and $85.98 \%$ minimum efficiency at $5 \mathrm{~W}$ input. Thus, it is clear that the recommended CPC topology has shown an excellent efficiency with high voltage gain. Figure 15 shows the output voltages at altered duty cycles, where it can be simply observed that at any duty cycle, recommended converter achieved high voltage at the output in response to the conventional converter. Furthermore, in Figure 16, the switching stress and output voltage across the MOSFETs of recommended CPC converter and traditional boost converter are illustrated, where we can witness that at $0.4,0.5$, and 0.6 duty ratio levels, voltage gain of the proposed converter is very high and switching stress is low as compared to traditional boost converter, and the voltage gain is equal to voltage stress across the MOSFET switch.

\section{Conclusions}

Renewable energy systems are needed in order to meet the increasing demand of the global energy consumption, and power electronic converters are an important module in such systems. This paper presents new DC-DC boost converters based on the charge pump capacitor (CPC). The feature combination of CPC-DCBC with voltage multiplier cell attains high output voltage gain with lesser switching stress. After simulation and experimental results, it is evidenced that the CPC-DCBC proposed topology could achieve high output voltage without working at an extremely duty cycle with excellent efficiency. The presented converter topology is applicable where a grid supply is unavailable and the source appliances generally run at high current with low input voltage, whereas their output load requirement is low current with high output voltage. for example, remote telecommunication system, off-grid solar system, and defense communication system. It also has the following advantages over traditional DC-DC boost converter:

(i) It operates at a lower duty cycle, which reduces the losses linked with the components installed in circuit and improves its efficiency

(ii) Less number of components, which reduce the risk of malfunctioning across the components and can, therefore, achieve higher voltage gain with very less voltage stress

(iii) Fewer switch utilization because of low voltage stress across them, which tends to reduce the active switch cost

(iv) Smaller inductor size because of less energy volume, which reduces the cost and size of the converter

\section{Data Availability}

The raw data used for this proposed work have been cited in the manuscript. Moreover, the derived data supporting the findings of this study have been graphically depicted and are available with the corresponding author on request.

\section{Conflicts of Interest}

The authors declare that there is no conflict of interest regarding the publication of this paper.

\section{Acknowledgments}

Authors thankfully acknowledged the support and funding provided by the Scientific Research Deanship, King Khalid University, Kingdom of Saudi Arabia, for the Large Research Group under the grant number R.G.P2./82/41.

\section{References}

[1] M. Sahoo and K. S. Kumar, "High gain step up DC-DC converter for DC micro-grid application," in 7th International Conference on Information and Automation for Sustainability, pp. 1-5, Colombo, Sri Lanka, 2014.

[2] A. Naderi and K. Abbaszadeh, "High step-up DC-DC converter with input current ripple cancellation," IET Power Electronics, vol. 9, no. 12, pp. 2394-2403, 2016.

[3] A. A. A. Freitas, F. L. Tofoli, E. M. Sá Júnior, S. Daher, and F. L. M. Antunes, "High-voltage gain $\mathrm{dc}-\mathrm{dc}$ boost converter with coupled inductors for photovoltaic systems," IET Power Electronics, vol. 8, no. 10, pp. 1885-1892, 2015.

[4] L. Kouchachvili, W. Yaïci, and E. Entchev, "Hybrid battery/supercapacitor energy storage system for the electric vehicles," Journal of Power Sources, vol. 374, pp. 237-248, 2018.

[5] S. Chakrabarti and S. Chakrabarti, "Rural electrification programme with solar energy in remote region-a case study in an island," Energy Policy, vol. 30, no. 1, pp. 33-42, 2002. 
[6] S.-W. Lee and H.-L. Do, "High step-up coupled-inductor cascade boost DC-DC converter with lossless passive snubber," IEEE Transactions on Industrial Electronics, vol. 65, no. 10, pp. 7753-7761, 2018.

[7] D. Thenathayalan, C. Lee, and J.-H. Park, "High-order resonant converter topology with extremely low-coupling contactless transformers," IEEE Transactions on Power Electronics, vol. 31, no. 3, pp. 2347-2361, 2015.

[8] A. Tomaszuk and A. Krupa, "Step-up DC/DC converters for photovoltaic applications-theory and performance," Electrical Review, vol. 89, pp. 51-57, 2013.

[9] T. Kim, D. Feng, M. Jang, and V. G. Agelidis, "Common mode noise analysis for cascaded boost converter with silicon carbide devices," IEEE Transactions on Power Electronics, vol. 32, no. 3, pp. 1917-1926, 2016.

[10] H. Wang and Z. Li, "A PWM LLC type resonant converter adapted to wide output range in PEV charging applications," IEEE Transactions on Power Electronics, vol. 33, no. 5, pp. 3791-3801, 2017.

[11] H. Wu, X. Zhan, and Y. Xing, "Interleaved LLC resonant converter with hybrid rectifier and variable-frequency plus phaseshift control for wide output voltage range applications," IEEE Transactions on Power Electronics, vol. 32, no. 6, pp. 42464257, 2017.

[12] M. Z. Malik, A. Ali, Q. Xu, and G. Chen, "A new quadratic boost converter with voltage multiplier cell: an analysis and assessment," International Journal of Smart Home, vol. 10, no. 8, pp. 281-294, 2016.

[13] A. Haque, A. Alshareef, A. I. Khan, M. M. Alam, V. S. B. Kurukuru, and K. Irshad, "Data description technique-based islanding classification for single-phase grid-connected photovoltaic system," Sensors, vol. 20, no. 11, p. 3320, 2020.

[14] M. Z. Malik, H. Chen, M. S. Nazir et al., "A new efficient stepup boost converter with CLD cell for electric vehicle and new energy systems," Energies, vol. 13, no. 7, article 1791, 2020.

[15] M. Z. Malik, Q. Xu, A. Farooq, and G. Chen, "A new modified quadratic boost converter with high voltage gain," IEICE Electronics Express, vol. 14, no. 1, 2017.

[16] M. Z. Malik, A. Farooq, A. Ali, and G. Chen, "A DC-DC boost converter with extended voltage gain," MATEC Web of Conferences, vol. 40, article 07001, 2016.

[17] J. Leyva-Ramos, R. Mota-Varona, M. G. Ortiz-Lopez, L. H. Diaz-Saldierna, and D. Langarica-Cordoba, "Control strategy of a quadratic boost converter with voltage multiplier cell for high-voltage gain," IEEE Journal of Emerging and Selected Topics in Power Electronics, vol. 5, no. 4, pp. 1761-1770, 2017.

[18] J. R. Garcia-Sanchez, E. Hernandez-Marquez, J. RamirezMorales et al., "A robust differential flatness-based tracking control for the "MIMO DC/DC boost converter-inverter-DC motor' system: experimental results," IEEE Access, vol. 7, pp. 84497-84505, 2019.

[19] S. Malek, "A new nonlinear controller for DC-DC boost converter fed DC motor," International Journal of Power Electronics, vol. 7, no. 1/2, pp. 54-71, 2015.

[20] A. Richelli, L. Colalongo, S. Tonoli, and Z. M. Kovacs-Vajna, "A 0.2-1.2 V DC/DC boost converter for power harvesting applications," IEEE Transactions on Power Electronics, vol. 24, no. 6, pp. 1541-1546, 2009.

[21] M. Maalandish, S. H. Hosseini, S. Ghasemzadeh, E. Babaei, R. Shalchi Alishah, and T. Jalilzadeh, "Six-phase interleaved boost DC/DC converter with high-voltage gain and reduced voltage stress," IET Power Electronics, vol. 10, no. 14, pp. 1904-1914, 2017.

[22] M. S. B. Ranjana, N. S. Reddy, and R. K. P. Kumar, “A novel high gain floating output DC-DC multilevel boost converter for fuelcell applications," in 2014 International Conference on Circuits, Power and Computing Technologies [ICCPCT-2014], pp. 291-295, Nagercoil, India, 2014.

[23] T. Roy Choudhury and B. Nayak, "Comparative steady state analysis of boost and cascaded boost converter with inductive esr losses \& capacitor current behaviour," International Journal of Power Electronics and Drive Systems (IJPEDS), vol. 7, no. 1, p. 159, 2016.

[24] H. Ardi, A. Ajami, F. Kardan, and S. N. Avilagh, "Analysis and implementation of a nonisolated bidirectional DC-DC converter with high voltage gain," IEEE Transactions on Industrial Electronics, vol. 63, no. 8, pp. 4878-4888, 2016.

[25] S. B. Mahajan, P. Sanjeevikumar, P. Wheeler, F. Blaabjerg, M. Rivera, and R. Kulkarni, "X-Y converter family: a new breed of buck boost converter for high step-up renewable energy applications," in 2016 IEEE International Conference on Automatica (ICA-ACCA), pp. 1-8, Curico, Chile, 2016.

[26] M. Lotfi Nejad, B. Poorali, E. Adib, and A. A. Motie Birjandi, "New cascade boost converter with reduced losses," IET Power Electronics, vol. 9, no. 6, pp. 1213-1219, 2016.

[27] M. Z. Malik, A. Ali, and D. Kumar, "A two cascaded boost converter with high voltage gain module," International Journal of Computer and Electrical Engineering, vol. 9, no. 2, pp. 476-483, 2017.

[28] A. Farooq, Z. Malik, D. Qu, Z. Sun, and G. Chen, "A threephase interleaved floating output boost converter," Advances in Materials Science and Engineering, vol. 2015, Article ID 409674, 8 pages, 2015.

[29] F. Akar, Y. Tavlasoglu, E. Ugur, B. Vural, and I. Aksoy, “A bidirectional nonisolated multi-input DC-DC converter for hybrid energy storage systems in electric vehicles," IEEE Transactions on Vehicular Technology, vol. 65, no. 10, pp. 7944-7955, 2015.

[30] I.-M. Pop-Calimanu, S. Lica, S. Popescu, D. Lascu, I. Lie, and R. Mirsu, "A new hybrid inductor-based boost DC-DC converter suitable for applications in photovoltaic systems," Energies, vol. 12, no. 2, p. 252, 2019.

[31] J. Sun, X. Ding, M. Nakaoka, and H. Takano, "Series resonant ZCS-PFM DC-DC converter with multistage rectified voltage multiplier and dual-mode PFM control scheme for medicaluse high-voltage X-ray power generator," IEE Proceedings Electric Power Applications, vol. 147, no. 6, pp. 527-534, 2000. 